\title{
EL ESTADO DE COSAS INCONSTITUCIONAL COMO UN MECANISMO DE EXIGIBILIDAD DE RESPETO Y GARANTÍA DE LOS DERECHOS HUMANOS EN COLOMBIA Y SU APLICACIÓN EN BRASIL POR LA CORTE SUPREMA \\ ESTADO DE COISAS INCONSTITUCIONAL COMO MECANISMO DE EFETIVIDADE E GARANTIA DOS DIREITOS HUMANOS NA COLOMBIA E SUA APLICAÇÃO NO BRASIL PELA SUPREMA CORTE
}

Omar Huertas Díaz

Profesor Asociado, Doctor en Derecho, Universidad Nacional de Colombia, PhD en Ciencias de la Educación, Universidad Simón Bolívar. Mg. en Derecho Penal Universidad Libre, Máster en Derechos Humanos, Estado de Derecho y Democracia en Iberoamérica Universidad de Alcalá, España.

Mg. en Educación Universidad Pedagógica Nacional

Ana Alice De Carli Professora Adjunta do Curso de Direito e do Mestrado em Tecnologia Ambiental da Universidade Federal Fluminense (UFF/UFF). Doutora e Mestre em Direito Publico e Evolução Social. Especialista em Direito Público. Membro da Comissão de Meio Ambiente da Ordem dos Advogados do Brasil, seção Rio de Janeiro. Pesquisadora fundadora do Grupo de Estudos em Meio Ambiente e

Direito - GEMADI/UFF.

Bruno de Paula Soares

Graduando em Direito pela Universidade Federal Fluminense. Orientando dos professores doutores Ana Alice De Carli e Omar Huertas Díaz. Monitor da Disciplina de Direito Financeiro e

Tributário do Curso de Direito da UFF/VR. Estagiário da Procuradoria da Fazenda Nacional.

Submissão em 02/07/2017

Aprovação em 03/07/2017

DOI: http://dx.doi.org/10.21671/rdufms.v3i1.4096 
Resumen: Indiscutiblemente, en las últimas dos décadas la sociedad colombiana ha sido testigo y participe de las transformaciones más importantes que ha sufrido el Estado, tanto del rediseño de la estructura organizacional del poder, así como del reconocimiento progresivo de un amplio catálogo de derechos fundamentales en su carta política. En ese sentido, las transformaciones en estas dos áreas han traído como consecuencia la existencia de un mayor parámetro de exigibilidad de respeto y garantía de los derechos humanos; para cumplir con ello, se han implementado novedosos y complejos mecanismos procesales para su defensa, tal como lo es la declaratoria del estado de cosas inconstitucional. Dicho desarrollo guarda especial relevancia, ya que sirve de modelo y guía para los países latinoamericanos, pues con ello se pretende la intervención colectiva de los poderes públicos y superar las falencias de carácter estructural de las políticas públicas, hacer frente y disminuir las violaciones masivas y sistemáticas de los derechos fundamentales y con ello reintegrar el valor máximo del ser humano que es su dignidad. Por último, se demuestra que en Brasil, aunque tímidamente, la doctrina jurisprudencial del estado de cosas inconstitucional ha sido aplicada por la Suprema Corte de aquel país.

Palabras clave. Constituición; Dignidad Humana; Políticas públicas, Estado de Cosas; Derechos Humanos.

Resumo: Inegavelmente, nas últimas duas décadas a sociedade colombiana tem sido testemunha das transformações ocorridas no contexto socio-juridico, as quais implicam um redesenho da estrutura organizacional do poder, bem como o reconhecimento progressivo de uma ampla gama de direitos fundamentais, na sua carta política. Nesse sentido, tais mudanças implicam a construção de um parâmetro importante de efetividade e garantia dos direitos humanos, que é a declaração do estado de coisas inconstitucional. Tal construção jurídica pode servir como um modelo e guia para países da América Latina, visto que se destina à superação das deficiências de natureza estrutural das políticas públicas, ao enfrentamento e à reduzição das violações massivas e sistemáticas dos direitos fundamentais e, com isso, reintegrar o valor máximo do ser humano, que é sua dignidade. Por fim, visa-se a demonstrar que no Brasil, ainda que tímidamente, a tese do estado de coisas inconstitucional vem sendo aplicado pela Suprema Corte.

Palavras-chave: Constituição; Dignidade da pessoa humana; Políticas Públicas; Estado de Coisas Inconstitucional; Direitos Humanos.

SUMÁRIO: 1. Introducción. 2. Declaración del estado de cosas inconstitucional en Colombia. 3. La protección de los derechos humanos a partir del activismo judicial. 4. La aplicación de la doctrina jurisprudencial del estado de cosas inconstitucional en Brasil por la Corte Suprema. 5. La Acción de Arguición de Incumplimiento de Precepto Fundamental (ADPF) no 347/DF: breve análisis y la aplicación de la doctrina del estado de cosas inconstitucional. Conclusión. Referencias.

\section{INTRODUCCIÓN}

En este artículo se utilizan dos perspectivas metodológicas: la analítica y comparativa. La perspectiva analítica permite buscar, analizar y descomponer todos los conceptos y definiciones de los temas que se pretenden abarcar, aclarar los conceptos, sus alcances y límites desde un punto de vista crítico y propositivo. Con la perspectiva comparativa se buscará la comparación sistemática de casos de análisis con la finalidad de la verificación de hipótesis. 
La República de Colombia vive actualmente desafíos trascendentes para cumplir con su carta política, cuya vigencia data del 20 de julio de 1991, así como con el gran entramado de derechos humanos que se consagran en la legislación y en el amplio número de tratados internacionales suscritos en la materia, los cuales representan sin duda alguna las actuales aspiraciones de la sociedad.

Es importante señalar, que la Constitución de 1991, además de sus implicaciones constitucionales y jurídicas, configuró en Colombia un proyecto social-democrático de modernidad política, pluralista y tolerante, enfrentándose a todas aquellas tradiciones y fines anacrónicos derivados de la constitución de 1886 (QUINTANA, 2012, pág. 185).

En ese mismo sentido, Quinche Ramírez, al referirse a la constitución de 1991, la describe como un texto democrático, participativo y pluralista, toda vez que el texto ha incluido las demandas de muy diversos sectores sociales, precisando que:

[...] al lado de los políticos y de los aristócratas de las regiones, tomaron asientos como constituyentes, personas venidas de los más diversos orígenes. Hubo allí estudiantes, líderes sociales, políticos, miembros de comunidades religiosas, sindicalistas, intelectuales, indígenas, afrocolombianos y sujetos de otros sectores, ejercitando una experiencia participativa jamás ensayada en el país (RAMÍREZ, 2012, pág. 13).

No cabe la menor duda de que la promulgación de una nueva constitución en 1991 trajo consigo el hecho como tal, una innegable transformación profunda, toda vez que, en el rediseño de la estructura del Estado y sus instituciones de la vida política, en la que existió la participaron un gran número de sectores sociales, quienes se hicieron escuchar, para efecto de rediseñar y plasmar los derechos y aspiraciones que se pretendían que fueran garantizados y materializados.

Para cumplir con dichas aspiraciones, es el Estado organizado, que se despliega en todas sus instituciones y órganos, el encargado de que la constitución se conviertan en una realidad y no se queden en simples supuestos ideológicos o metafísicos. Esta organización implica la forma en que habrá de integrarse, estructurarse y ejercitarse el poder político, pero además debe poner a disposición de los gobernados aquellos mecanismos o medios de control que permitan restituir el orden y los derechos conculcados ante cualquier acto autoritario, todo lo anterior, “con la finalidad de garantizar el bien común” (NÚÑEZ, 2013, pág. 138)

Es aquí, donde ha jugado un papel relevante la actuación proactiva que ha tenido la Corte Constitucional de Colombia en los últimos años, frente a las graves violaciones a los derechos humanos, lo cual se puede constatar en el importante desarrollo jurisprudencial que ha acuñado, y del cual tiene su origen la figura que 
nos proponemos analizar en éste trabajo, nos referimos a la declaración de estado de cosas inconstitucional, misma que tiene por finalidad, la protección de los derechos humanos cuyas violaciones posean un carácter general y cuyas causas tengan un carácter estructural.

Por ello, la Corte Constitucional ha desempeñado un papel fundamental en la garantía de los derechos humanos frente al abuso del poder, en el que además, no solo se ha convertido en revisora de los actos de la autoridad, sino que ha tenido un papel muy activo de coordinación y dialogo con todos los poderes para hacer, cada día más vigente el modelo de estado social y democrático de derecho que proclama la Carta política de 1991; y con ello superar los desafíos actuales en torno al respeto y garantía de los derechos humanos, pues hoy en día aún existen vacíos y fallas estructurales en la vida nacional, mismas que han permitido que en el país colombiano se violen de manera sistemática y reiterativa los derechos fundamentales de quienes habitan en el país, afectando con ello el principio básico y fundante del estado social de derecho, me refiero a la dignidad humana (CONSTITUYENTE, 1991).

\section{DECLARACIÓN DEL ESTADO DE COSAS INCONSTITUCIONAL EN COLOMBIA}

La Republica de Colombia cuenta con importantes instrumentos jurídicos y entes encargados de velar por el cumplimiento y salvaguardia del contenido constitucional, así como del contenido que deviene del derecho interno de fuente internacional - tratados internacionales - mismos que contienen un amplio abanico de derechos humanos que se les reconocen a los habitantes del país colombiano.

Uno de ellos es la Corte Constitucional de Colombia, la cual, de conformidad con el artículo 241 de la constitución, se le confía la guarda de la integridad y supremacía de la Constitución, pero además, guarda una función relevante, pues tal y como lo sostiene Cepeda Espinoza dicha corte "ha concentrado sus esfuerzos en la protección de los derechos fundamentales de los individuos y grupos de la sociedad, esta labor ha sido de gran importancia para los grupos poblacionales más vulnerables”. (CEPEDA ESPINOZA, 2001, pág. 21)

Así mismo, como principal institución jurídica de protección de los derechos fundamentales que se consagran dentro de la constitución y de los tratados internacionales, y a la cual puede acceder cualquier persona, es el que se contiene el artículo 86 de la constitución, nos referimos a la acción de tutela, la cual fue perfeccionada por decreto del entonces presidente Cesar Gaviria dentro de la ley 2591, la cual, de conformidad con el artículo en cita, reza de la siguiente manera: 
Toda persona tendrá acción de tutela para reclamar ante los jueces, en todo momento y lugar, mediante un procedimiento preferente y sumario, por sí misma o por quien actúe a su nombre, la protección inmediata de sus derechos constitucionales fundamentales, cuando quiera que éstos resulten vulnerados o amenazados por la acción o la omisión de cualquier autoridad pública. (CONSTITUYENTE, 1991).

Resulta claro que, por mandamiento de la carta política colombiana, la acción de tutela es el mecanismo por excelencia de protección de los derechos fundamentales de las personas naturales o jurídicas cuyos derechos están siendo vulnerados o amenazados, siempre y cuando no exista otro medio de defensa judicial eficaz.

Asimismo, resulta importante señalar que, por medio de la acción de tutela, y ante la necesidad de salvaguardar los derechos constitucionales de amplios sectores de la población colombiana, es que la Corte constitucional como guardián de la ley fundamental, ha hecho un desarrollo jurisprudencial de dicha institución jurídica, a lo cual se le ha denominado la declaratoria del estado de cosas inconstitucional.

Mendoza Martelo, al realizar un análisis sobre el tema en comento, señala que toda decisión de la Corte Constitucional supone la presencia de preceptos constitucionales como fundamento (SCJN-Oficina en México del Alto Comisionado de Naciones Unidas, 2014, pág. 423), de manera tal que el estado de cosas inconstitucional tiene como base y se sustenta en los siguientes preceptos constitucionales $1^{\circ}, 2^{\circ}, 13,113$, y 334 , mismos que precisan:

Art. 1) el modelo de estado social de derecho; Art. 2) los fines del estado que principalmente se traducen en garantizar la efectividad de los principios, derechos y deberes consagrados en la Constitución, Art. 13) la obligación de promover las condiciones de igualdad a favor de los grupos marginados y sancionar los abusos contra éstos, Art. 113) la obligación de los órganos del estado de colaborar armónicamente para la realización de sus fines, y finalmente, Art. 334) la dirección general de la economía del estado para cumplir con los objetivos del modelo de estado social y democrático de derecho.

Ahora bien, como se puede advertir, la figura del estado de cosas inconstitucional ha sido creada jurisprudencialmente con el objetivo de garantizar el cumplimiento de los fines del Estado, así como garantizar los derechos y deberes constitucionales, buscando contrarrestar y corregir las violaciones a los derechos humanos que requieren de un tratamiento especial por parte de los órganos del estado en su conjunto.

En palabras de la propia Corte Constitucional de Colombia esta figura, se ha creado (Establecimiento carcelario, condiciones de hacinamiento, 1998)“con el 
fin de buscar remedio a situaciones de vulneración de los derechos fundamentales que tengan un carácter general - en tanto que afectan a multitud de personas", es por medio de este desarrollo, y en apoyo al principio de igualdad, que la Corte ha hecho extensivo los efectos de la acción de tutela, para el efecto de ordenar la reparación integral de la situación que impera y con ello evitar que continúen las violaciones graves y sistemáticas de un abanico de derechos de un grupo de la población en específico.

Es importante señalar que, el desarrollo jurisprudencial del estado de cosas inconstitucional, ha presentado variaciones a lo largo de su desarrollo y estructuración, por lo que debemos señalar que la misma se encuentra en constante evolución, desde el surgimiento de la figura con la sentencia SU-559 del 6 de noviembre de 1997,dentro de la cual la Corte constitucional por medio de este mecanismo pretendió resolver la vulneración de los derechos fundamentales de un grupo de docentes derivada de la omisión de su afiliación a un fondo de prestaciones sociales, en la que la Corte declaró la existencia de un "estado de cosas contrario a los preceptos constitucionales".

A partir de dicha sentencia se han acumulado varios elementos para efecto de determinar si existe un estado de cosas inconstitucional, la Corte ha expuesto 5 factores a valorar, dentro de los cuales se señalan los siguientes:

(i) la vulneración masiva y generalizada de varios derechos constitucionales que afecta a un número significativo de personas;

(ii) la prolongada omisión de las autoridades en el cumplimiento de sus obligaciones para garantizar los derechos;

(iii) la adopción de prácticas inconstitucionales, como la incorporación de la acción de tutela como parte del procedimiento para garantizar el derecho conculcado;

(iv) la no expedición de medidas legislativas, administrativas o presupuestales necesarias para evitar la vulneración de los derechos.

(v) la existencia de un problema social cuya solución compromete la intervención de varias entidades, requiere la adopción de un conjunto complejo y coordinado de acciones y exige un nivel de recursos que demanda un esfuerzo presupuestal adicional importante;

(vi) si todas las personas afectadas por el mismo problema acudieran a la acción de tutela para obtener la protección de sus derechos, se produciría una mayor congestión judicial. (Estado de cosas incosntitucional de la población desplazada, 2004).

Seis factores que tienden a romper con el esquema tradicional de la acción de tutela, pues mientras esta tiene efectos inter partes, el estado de cosas inconstitucional tiene efectos generales, es decir inter comunis, pues tal y como se des- 
prende del primer factor, esta surge de la vulneración masiva y generalizada de varios derechos que afectan a una pluralidad de individuos.

Tenemos que precisar que una característica de la acción de tutela son los efectos inter partes, los cuales son una regla general de dicha institución, toda vez que a través de la acción se resuelve violaciones a los derechos humanos del solicitante, esto atendiendo a la petición que eleva la víctima, por la acción u omisión de la autoridad violadora de los derechos fundamentales reconocidos en la constitución y en tratados internacionales.

Sin embargo, de manera excepcional el fallo puede tener efectos inter comunis, en ese sentido la Corte Constitucional ha precisado que "hay eventos excepcionales en los cuales los límites de la vulneración deben fijarse en consideración tanto del derecho fundamental del tutelante como del derecho fundamental de quienes no han acudido a la tutela" (DERECHO A LA SEGURIDAD SOCIAL DE PERSONA DE LA TERCERA EDAD, 2001). De aquí se desprende la doctrina jurisprudencial del estado de cosas inconstitucional.

Ello se debe a que la "Corte asume un papel mucho más comprometido con la sociedad y sobre todo con aquellos sectores más vulnerables de la misma, en la medida en que se da a la tarea de buscar soluciones definitivas a los problemas de naturaleza estructural que se presentan en el país" (QUINTERO LYONS, 2011, pág. 1), ante estos retos de vulneración masiva y generalizada, es claro que sobrepasan la órbita de control de la acción de tutela, la cual es exclusiva de la persona que solicita la protección de la justicia.

Por cuanto se refiere al primer punto, es claro que la vulneración masiva, generalizada y sistemática de los derechos fundamentales de las personas sobrepasan la órbita de control de la acción de tutela, la cual es exclusiva de la persona que solicita la protección de la justicia, pero además, esta vulneración es seguida de la omisión de las autoridades para atender tal situación, lo que implica la imposibilidad de corregir las principales falencias de ese estado de cosas inconstitucional, permitiendo la repetición y prolongación de las violaciones a través del tiempo.

Una observación que no debemos dejar pasar es que, al ser generalizadas las prácticas inconstitucionales por parte de las autoridades, esto trae como consecuencia que las personas utilicen la acción de tutela para efecto de que se les proteja y restituya en cuanto a la vulneración de sus derechos, pero al ser masiva la vulneración, se da un fenómeno de congestión del sistema judicial de todos aquellos que acuden a solicitar la tutela.

Por cuanto corresponde a las omisiones legislativas, administrativas y presupuestales que traen como consecuencia que las violaciones masivas sean de 
naturaleza estructural, la Corte ha señalado que "su solución exige la acción mancomunada de distintas entidades" (Establecimiento carcelario, condiciones de hacinamiento, 1998, pág. 2). Atendiendo a ello, se reclama al conjunto de autoridades omisas la realización de las acciones y asignación del presupuesto necesario y suficiente para erradicar la situación contraria a los derechos humanos, por lo que estamos frente a una obligación de tipo mancomunado.

Por otra parte, atendiendo al punto tercero y quinto de los factores en comento, es importante referirnos que al ser generalizadas las prácticas inconstitucionales por parte de las autoridades, esto traerá como consecuencia que las personas utilicen la acción de tutela para efecto de que se les proteja y restituya en cuanto a la vulneración de sus derechos, pero al ser masiva la vulneración, se da un fenómeno de congestión del sistema judicial de todos aquellos que acuden a solicitar la tutela.

Por cuanto hace a los puntos cuarto y quinto, la corte ha señalado en su sentencia T-153-98 que las omisiones legislativas, administrativas y presupuestales "son causas de naturaleza estructural - es decir que, por lo regular, no se originan de manera exclusiva en la autoridad demandada y, por lo tanto, su solución exige la acción mancomunada de distintas entidades". Por lo que se exige al conjunto de autoridades omisas realicen las acciones y destinen el presupuesto necesario y suficiente para erradicar la situación contraria a los derechos humanos, por lo que estamos frente a una obligación de tipo mancomunado.

De todo lo anteriormente expuesto, se puede estar en condiciones de definir que el estado de cosas inconstitucional:

[...] se predica de aquellas situaciones en las que se presenta una repetida violación de derechos fundamentales de muchas personas - que pueden entonces recurrir a la acción de tutela para obtener la defensa de sus derechos y colmar así los despachos judiciales - y cuando la causa de esa vulneración no es imputable únicamente a la autoridad demandada, sino que reposa en factores estructurales (Vulneración de los derechos fundamentales de las personas privadas de la libertad, 2015, pág. 75).

La importancia de la misma radica en que el estado de cosas inconstitucional identifica una serie de violaciones de derechos humanos que no pueden ser toleradas en un estado social y democrático de derecho; y que su vez, requieren de la acción coordinada, conjunta y compleja, de los poderes estatales para superar las fallas estructurales que han permitido la vulneración de los derechos de una colectividad.

Figura que se emplea para constatar que "alguna situación particular del texto constitucional carece de efectividad en el plano de la realidad, tornándose 
meramente formal" (Vulneración de los derechos fundamentales de las personas privadas de la libertad, 2015, pág. 74). Por lo que se decreta el desconocimiento de los derechos constitucionales en la actuación de diversas autoridades, y se hacen claras las omisiones en que se incurren, lo que genera que desde sus respectivas competencias se atente con el marco de derechos humanos y de las obligaciones de respeto y garantía de los mismos.

Es por ello que la figura del estado de cosas inconstitucional obliga a que las políticas públicas sean sensibles a los retos de gran calado que conllevan los derechos humanos, que estas tengan una perspectiva guiada y orientadas por los mismos, en esta parte la Corte ha sentado en sus resoluciones que "una política pública no es el conjunto de promesas y de directrices que una autoridad pública formula en un texto. Una política pública la constituye el conjunto de acciones y omisiones de una autoridad sobre una cuestión" (ESTADO DE COSAS INCONSTITUCIONAL DEL SISTEMA CARCELARIO, 2013) En ese sentido, estas deben de contar con una dimensión prestacional de los derechos y libertades fundamentales señaladas y que se exigen en el Bloque de constitucionalidad.

Por otra parte, y para superar la declaratoria del estado de cosas, la Corte constitucional ha ordenado una serie de medidas para poder superarlo, las cuales consisten en que:

1) se diseñen y pongan en marcha las políticas, planes y programas que garanticen de manera adecuada los derechos fundamentales cuyo goce efectivo depende de la superación del estado de cosas inconstitucional;

2) se apropien los recursos necesarios para garantizar la efectividad de tales derechos;

3) se modifiquen las prácticas, las fallas de organización y de procedimiento que resultan violatorias de la Constitución;

4) se reforme el marco jurídico cuyas falencias han contribuido al estado de cosas inconstitucional; y

5) se realicen los trámites administrativos, presupuestales y de contratación que sean indispensables para superar la vulneración de los derechos (Corte Constitucional de Colombia, 2004, pág. 84).

Aquí, es importante señalar que, las decisiones de la Corte Constitucional han impactado en las acciones de los otros poderes, toda vez que dicha figura ha motivado que se lleven a cabo actos de tipo no solo administrativo, como es el caso de las políticas públicas, sino que la misma ha influenciado el ámbito legislativo, como es el caso de la creación de la ley 1448 de 2011; el decreto 1660 de 2007 que reglamentó parcialmente el artículo 19 de la Ley 387 de 1997; el decreto 790 de 2012, entre otros (SCJN-Oficina en México del Alto Comisionado de Naciones Unidas, 2014, pág. 438). 
En cuanto se refiere a las políticas públicas, es necesario recalcar que en todo momento la Corte Constitucional se ha involucrado en la formación de las mismas, así como en la vigilancia de estricta aplicación, las cuales se encaminan a corregir el estado de cosas inconstitucional. Al respecto García Jaramillo señala tres etapas en las que participa la Corte con relación a la política pública:

a) interviene protegiendo un derecho social en un caso concreto mediante una orden específica de garantía a ese derecho;

b) imparte otra orden para que se diseñe un programa de atención integral, luego de confrontar la realidad con un juicio de naturaleza constitucional;

c) además de impartir órdenes estructurales con remedios, establece plazos (JARAMILLO, 2015, pág. 209).

Como podemos observar, la Corte Constitucional no concluye su labor con el dictado de una sentencia, es decir una simple labor jurisdiccional, sino que asume su papel más activo, para alcanzar los fines del estado social de derecho, involucrando al resto de los órganos e instituciones del Estado, tomando en cuenta a la población más vulnerada en cuanto a sus derechos. Sin duda alguna, dicho activismo judicial implica una verdadera garantía y tutela de los derechos.

Por cuanto se refiere al plano internacional, no debemos perder de vista que la vulneración de los derechos fundamentales de carácter general y cuyas causas correspondan a una naturaleza estructural, no sólo transgreden las obligaciones domésticas que derivan del código político colombiano, sino que contravienen las disposiciones de la Convención Americana de Derechos Humanos.

Instrumento donde se encuentran los pilares en que descansa la mayor protección y en donde se concentran las más importantes obligaciones generales que los Estados parte tienen para cumplir con los derechos y libertades en el ámbito interamericano, y que en palabras del Juez interamericano Eduardo Ferrer Mac-Gregor son la piedra angular del sistema interamericano (Ferrer Mac-Gregor Poisot, 2013), estos son los artículos $1^{\circ}$ y $2^{2}$ del citado instrumento, los cuales son la base de todas las sentencias que ha dictado por más de treinta años la Corte Interamericana de Derechos Humanos, artículos que guardan especial importancia para hacer valer los derechos esenciales del hombre contenidos en este importante instrumento internacional.

En lo que respecta al Artículo 1ํo del Pacto San José, se establece lo siguiente:

1. Los Estados Partes en esta Convención se comprometen a respetar los derechos y libertades reconocidos en ella y a garantizar su libre y pleno ejercicio a toda persona que esté sujeta a su jurisdicción, sin discriminación alguna por motivos de raza, color, sexo, idioma, religión, opiniones 
políticas o de cualquier otra índole, origen nacional o social, posición económica, nacimiento o cualquier otra condición social.

1.2. Para los efectos de esta Convención, persona es todo ser humano. (AMERICANOS, 1969, pág. 1).

Tal y como se puede observar en este dispositivo, se encuentran dos obligaciones generales para los Estados parte de la citada Convención, entre los que se incluye a Colombia, los cuales son fundamentales para poder cumplir con los derechos y libertades de las personas que se consagran, estas son las obligaciónes de respeto y de garantía de los derechos humanos.

Si el país es omiso en el respeto y garantía de los derechos humanos contenidos en la Convención Americana, todo esto parece confirmar que se estaría ante un estado de cosas inconvencionales, pues no solo se estaría inobservando y ofendiendo el catálogo nacional de derechos humanos, sino también el internacional, en específico de aquel que surge del seno del Sistema Interamericano.

En atención a lo anterior, ya ha sido señalado con gran atino por parte del Gobierno Colombiano que

[...] el respeto del orden jurídico en Colombia exige que, frente a la demanda de justicia, su aparato jurisdiccional resuelva los conflictos conforme al derecho aplicable, empezando por el bloque de constitucionalidad, para aplicar la Constitución Política, los Tratados Públicos y las leyes, sin perjuicio de los precedentes judiciales que sea necesario. (INFORME DEL GOBIERNO NACIONAL a la Corte Constitucional sobre la superación del Estado de Cosas Inconstitucional declarado mediante sentencia T-025 de 2004, 2010, pág. 24).

Con todo lo anterior, podemos afirmar que el papel que ha desempeñado la Corte Constitucional de Colombia - con la declaración del estado de cosas inconstitucional - corresponde al de una autoridad que busca cumplir con las obligaciones de respeto y garantía de los derechos humanos. Para lograrlo, la misma ha asumido un activismo judicial como coordinador y supervisor de algunas medidas que exigen la actuación urgente del resto de los poderes estatales, todo ello para cumplir con la constitución colombiana y los derechos que en ella se proclaman.

\section{LA PROTECCIÓN DE LOS DERECHOS HUMANOS A PARTIR DEL ACTIVISMO JUDICIAL}

En este apartado discutiremos brevemente sobre la importancia que guarda la labor democrática de los jueces en el estado de derecho, lo anterior, a partir 
de la emisión de sus resoluciones, pues el papel que desempeñen los jueces debe ser analizado en todo momento, destacando los avances en sus resoluciones - tal y como lo es la declaración de estado de cosas inconstitucional - y proponiendo una continuidad en la línea de protección de los derechos.

El enriquecimiento del desarrollo jurisprudencial obedece a que en el ámbito interno ha tenido gran influencia el derecho internacional de los derechos humanos, así como las decisiones de importantes tribunales supranacionales, el cual ha permitido la inclusión en los textos constitucionales latinoamericanos, así como la inclusión de las cláusulas de apertura como base de un complejo sistema de recepción del derecho internacional.

Ciertamente nos encontramos ante una reconfiguración del escenario jurídico latinoamericano y global, en el que el panorama jurídico contemporáneo se construye a partir de un entramado de interacciones heterárquicas (ALVARADO, 2015, pág. 19), con muy diversos alcances que se van definiendo a partir de la actuación y respuesta de muy diversos actores, entre ellos los actores judiciales en conjunto con otras autoridades e instituciones que conforman el gobierno nacional.

De acuerdo con los planteamientos anteriores, la justicia constitucional nacional exige una participación activa de los juzgadores, en la que se les exige dejar de ser simples aplicadores de las normas, es decir, los retos del nuevo orden jurídico integral llevan consigo que las autoridades judiciales dejen de ser simples revisores de la ley y se conviertan en auténticos defensores activos del corpus iuris internacional de los derechos humanos, y exigir en todo momento la materialización de los mismos.

Hemos de señalar que nos encontramos en un proceso evolutivo de la actividad jurisdiccional tendiente a la materialización del contenido constitucional, cuyo antecedente lo podemos ubicar a partir de procedimiento denominado judicial review proveniente del sistema legal anglosajón, cuyo predominio del contenido constitucional sobre las leyes fue resaltada por el juez Edward Coke, quien se pronunció sobre la validez de las leyes y su anulación por ser contrarias al derecho común, cuyo antecedente sirvió de base para que una vez iniciada la era del constitucionalismo, en la constitución norteamericana se estableciera la cláusula de supremacía constitucional y por consiguiente la vinculación a todas las autoridades incluidos los jueces, disposición que se vio materializada a partir del caso Marbury vs. Madison y su resolución dictada por el juez Marshall.

De lo anterior, García de Enterría plantea que dicha función es legitimadora del Tribunal Supremo, como ente guardián de la Constitución, calificando a la judicial review como la clave de bóveda de la construcción histórica de los Estados Unidos (MARTíNEZ -CARANDE, 2006, pág. 126), pero sobre todo con gran 
influencia en los sistemas jurídicos de los países hispanoparlantes, pues dicho instrumento ha servido de guía para el control de la constitucionalidad.

No perdamos de vista que el control constitucional llevado a cabo por las altas Cortes - y en algunos casos con distintos alcances por los tribunales y jueces locales -, del cual Hans Kelsen precisó que "las leyes atacadas de inconstitucionalidad son las que forman el principal objeto de la jurisdicción constitucional” (KELSEN, 2001, pág. 59), de allí la intervención del poder judicial en el ámbito legislativo.

Tampoco se debe olvidar que Kelsen advertía que si bien es cierto las leyes son el principal objeto del control constitucional, también debían someterse a este control todos los actos que acusen formas de leyes, aún y cuando éstos contengan normas individuales, tales como el reglamento del Parlamento o el voto del presupuesto, de ahí que sostuviese que el control debiera extenderse a los reglamentos que tienen fuerza de ley y de los simples reglamentos complementarios (KELSEN, 2001, pág. 63).

Ante los retos actuales y para evitar las profundas crisis sistemáticas en materia de derechos humanos que se viven en la región latinoamericana, tenemos que recordar el pensamiento del barón de Montesquieu, al señalar que "los jueces de la nación no son, según sabemos, sino la boca por donde habla la ley, seres inanimados que no pueden moderar ni su fuerza ni su rigor" (MONTEQUIEU, 2015, pág. 151), sino todo lo contrario, hoy en día ante los contextos mundiales y para alcanzar los objetivos y aspiraciones constitucionales, su actuación ya no se reduce en una simple revisión de las leyes y actos frente a la Constitución y sus fuentes, sino que además exige una actividad más elaborada que materialice el contenido que consagra los derechos fundamentales de millones de personas.

\section{LA APLICACIÓN DE LA DOCTRINA JURISPRUDENCIAL DEL ESTADO DE COSAS INCONSTITUCIONAL EN BRASIL POR LA CORTE SUPREMA ${ }^{1}$}

Sólo como breve introducción, cabe destacar que Brasil adopta un sistema mixto de control de constitucionalidad. De tal manera, se tiene el control en abstracto, por medio del cual la Corte Suprema analiza en tesis las leyes impugnadas en sede de Acción Directa de Inconstitucionalidad - por supuesto vicio de inconstitucionalidad.

A rigor, el primer sistema de control de constitucionalidad adoptado en el solo brasileño para el denominado sistema norteamericano, en el que los vicios

\footnotetext{
${ }^{1}$ La traducción de la lengua portuguesa a la española de este tópico fue realizada por la graduada em derecho de la Universidad Federal Fluminense - UFF / BRASIL e investigadora del Grupo de Estudios en Medio Ambiente y Derecho - GEMADI / UFF, Ana Julia Maturano.
} 
de inconstitucionalidad pueden ser examinados por cualquier órgano, no es un bojo de una acción en el curso, por lo que también se conoce como el control concreto y difuso (SARLET, 2015).

Cabe señalar también que, como ocurre en Colombia, la Corte Suprema de Justicia, el Supremo Tribunal Federal, es el guardián máximo de la Constitución de la República Federativa del Brasil de 1988, en los términos del art. 102 de la referida Carta Magna, correspondiendo a él el control de constitucionalidad de todas las normas jurídicas infraconstitucionales.

En ese contexto, la Suprema Corte brasileña (STF) posee un conjunto de instrumentos procesales, como la Acción Directa de Inconstitucionalidad; La Acción Directa de Inconstitucionalidad por omisión y la Acción de Arguición de Incumplimiento de Precepto Fundamental para examinar, en el control en abstracto leyes, los actos normativos considerados incompatibles con la Carta Magna vigente.

Se observa que las decisiones en el marco del control de la Constitución no siempre son fáciles, imponiendo la utilización por parte del STF de variadas técnicas, a ejemplo de la declaración de inconstitucionalidad parcial sin reducción de texto, de la interpretación conforme a la constitución. Los ministros de la Corte Suprema, al declarar "la inconstitucionalidad de ley o acto normativo, y teniendo en cuenta razones de seguridad jurídica o de excepcional interés social", determinan "por mayoría de dos tercios de sus miembros", ciertas restricciones o hasta incluso permiten que la decisión "sólo tenga eficacia a partir de su tránsito en juzgado o de otro momento que se fije”, con arreglo al artículo 27, de la Ley no 9.868 / 1999.

Es importante señalar, por oportuno, que la referida Corte de Justicia no cuida sólo del control de constitucionalidad, siendo atribuido por el texto constitucional una serie de otras competencias, como juzgar, en las hipótesis de infracciones penales comunes, el Presidente de la República, el Vicepresidente, los miembros del Congreso Nacional, sus propios Ministros y el Procurador General de la República, conforme establece el artículo 102 inciso I, letra b, de la Constitución Federal de 1988.

\section{LA ACCIÓN DE ARGUICIÓN DE INCUMPLIMIENTO DE PRECEPTO FUNDAMENTAL (ADPF) № 347 / DF: BREVE ANÁLISISY LA APLICACIÓN DE LA DOCTRINA DEL ESTADO DE COSAS INCONSTITUCIONAL}

Al mismo tiempo que el procesamiento de la ADPF 347/DF, sobre la declaración del Estado de Cosas Inconstitucionales en relación a las penitenciarías del país, el 
Supremo Tribunal Federal fue llamado a manifestarse en varias ocasiones, en casos concretos, sobre temas sensibles a la realidad carcelaria. Siguen dos ejemplos.

En el RE 580.252/MS, se discutió la compensación por daños morales causados por el Estado a los presos en razón de la coyuntura estructural del sistema penitenciario. En el pronunciamiento de voto de este recurso, el relator, ministro Teori Zavascki, acompañado por el ministro Gilmar Mendes, concluyó por la responsabilidad estatal al pago de fondos por daños morales a los detenidos. En el voto-vista, el ministro Luís Roberto Barroso aventuró la posibilidad de que los presos se beneficien de la remisión de pena cuando las condiciones de cumplimiento sean más gravosas que el establecido en la Ley de Ejecución Penal (Ley 7.210/1984). El mismo tema está siendo discutido en la ADI 5170.

En el RE 641.320 / RS, se enfrentó la realidad de presos que permanecían en el régimen cerrado en razón de la inexistencia de vacantes en otros establecimientos penitentes cuyos regímenes ya habían sido deferidos por el juez de la ejecución penal. EN este, el voto del relator, ministro Gilmar Mendes, dio preferencia al arresto domiciliario monitoreado e a penas alternativas, además de establecer obligación negativa a los jueces de ejecución en el sentido de vedar la restricción de detenidos a permanecer en régimen más gravoso.

En el marco del control en abstracto del Supremo Tribunal Federal, la primera acusación formal de Estado de Cosas Inconstitucional se refiere a las condiciones objetivas de cumplimiento de pena en las cárceles brasileñas. La ADPF 347/DF fue propuesta por el PSOL (Partido Socialismo y Libertad) en mayo de 2015 para, en el mérito, el reconocimiento de este instituto y la ejecución de las medidas prácticas de su declaración, y, cautelarmente, provisiones con el objetivo de atenuar las máculas por las que pasan los detenidos.

El partido sacó a la luz varias estadísticas sosteniendo la violación de derechos humanos experimentada en Brasil, entre ellas, números referendados por el Consejo Nacional de Justicia y por una Comisión Parlamentaria de Investigación realizada en 2009 sobre el sistema carcelario brasileño. Se trata de cifras reveladoras sobre la existencia de lechos, la escolaridad de los detenidos, las tasas de reincidencia y tantas otras de magnitud que reflejan las consecuencias de las acciones y omisiones por parte del Estado y de la sociedad en relación con la cuestión carcelaria.

Para fundamentar las solicitudes definitivas formuladas (entre ellos, el de la declaración del Estado de Cosas Inconstitucionales y el de la expedición de plan de metas por el Gobierno Federal para superarlo, sometiendo su control a órganos representantes de las instituciones democráticas, como la sociedad civil por de la audiencia pública, la $\mathrm{OAB}$, el Ministerio Público, la Fiscalía General 
de la Unión y la Defensoría General de la Unión), la petición inicial fue instruida con los elementos abstractos de la Teoría del Estado de Cosas Inconstitucionales, basándose en la doctrina, como dictámenes de juristas, y en la jurisprudencia colombiana, a saber, principalmente en la sentencia del proceso T-153/1998.

Cabe resaltar que, hasta el presente, sólo se han pronunciado los votos del ministro Marco Aurelio y del ministro Edson Fachin.

En las palabras del ministro Marco Aurelio, reconociendo los argumentos de hecho levantados en la inicial,

[...] no sería posible indicar, con seguridad, entre los muchos problemas de derechos enfrentados en Brasil [...] todos que encajen en ese concepto. Sin embargo, las dificultades en definir el alcance mayor del término no impiden, teniendo en cuenta el cuadro relatado, se consigna una zona de certeza positiva: el sistema carcelario brasileño se enmarca en la denominación de "estado de cosas inconstitucional".

En el juicio cautelar, deferiendo casi la totalidad de las medidas cautelares, el ministro Marco Aurelio reconoció que hay banalización de la prisión preventiva en Brasil, hipótesis en que presos quedan meses o incluso años a la espera de una decisión judicial de mérito. También reconoció que la audiencia de custodia contenida en el artículo 7.5 de la Convención Interamericana de Derechos Humanos debe ser implementada en Brasil, ya que el tratado ya fue internalizado en el ordenamiento. El ministro aclaró, en el voto, que los recursos del Fondo Penitenciario Nacional, en los últimos años, han sido contingenciados, impidiendo la inversión en la mejora de las condiciones de las cárceles.

En el voto del ministro Edson Fachin, fueron deferidas sólo las precauciones referentes a las solicitudes de realización de las audiencias de custodia, de los mutirones carcelarios para revisar procesos de ejecución penal en que la detención cautelar es innecesaria o excesiva y la liberación de los recursos del Fondo Penitenciario Nacional. El ministro Edson Fachin concluyó que los otros pedidos se confundían con el pedido de mérito de la acción, por lo que dejó para el análisis en el juicio final.

Sin embargo, la lectura del voto permite concluir que el ministro se alineó al entendimiento por la importancia del tema y por la declaración del Estado de Cosas Inconstitucionales:

Los establecimientos penitentes funcionan como instituciones segregacionistas de grupos en situación de vulnerabilidad social. Se encuentran separados de la sociedad los negros, las personas con discapacidad, los analfabetos. Y no hay muestras de que esa segregación objetive - un día - reintegrar a la sociedad, sino mantenerlos indefinidamente apartados, 
a partir de la contribución que la precariedad de los establecimientos ofrece a la reincidencia [...].

Se avecina un estado en que los derechos fundamentales de los presos, definitivos o provisionales, padecen de protección efectiva por parte del Estado.

Al confrontarse las peticiones cautelares con los votos de los dos ministros, se puede percibir una alineación determinante a favor del reconocimiento del Estado de Cosas Inconstitucionales en las cárceles brasileñas, que, en la ADPF 347 / DF, constituye una de las solicitudes principales, el cual será apreciado en el juicio definitivo de la acción.

\section{CONCLUSIÓN}

Para la materialización de los derechos humanos dentro del territorio colombiano, la sociedad ha exigido a los poderes el cumplimiento irrestricto de la carta política y de sus fuentes internas de derecho internacional, para ello, ha hecho uso de los instrumentos que la propia constitución señala, tal como lo es la acción de tutela, lamentablemente y ante la crisis sistemática en materia de derechos humanos que sufren grupos sociales que el estado ha identificado - población desplazada, personas recluidas en las cárceles, personas mayores, población en estado de indigencia, defensores de los derechos humanos, etc. - dicho instrumento ha sido insuficiente.

Para atender las situaciones en las que se advierten graves violaciones a los derechos humanos de una generalidad de personas en situación de vulnerabilidad, en las cuales se hacen patentes las fallas estructurales en las políticas públicas, la Corte Constitucional colombiana ha jugado un especial papel para atender tal situación y garantizar los derechos fundamentales, para ello, la misma a desarrollado por la vía jurisprudencial las figuras como la del estado de cosas inconstitucional.

Con este mecanismo se decreta el desconocimiento de los derechos constitucionales en la actuación de diversas autoridades, y se hacen claras las falencias $\mathrm{u}$ omisiones en que se incurren, lo que genera que desde sus respectivas competencias se atente con el marco de derechos humanos y de las obligaciones de respeto y garantía de los mismos.

Aquí es importante señalar que, mediante este desarrollo la Corte Constitucional se ha planteado el objetivo de garantizar el cumplimiento de los fines del Estado, así como garantizar los derechos y deberes constitucionales, buscando contrarrestar y corregir las violaciones a los derechos humanos que requieren de un tratamiento especial por parte de los órganos del estado en su conjunto. 
Dicho desarrollo jurisprudencial de la Corte Constitucional colombiana es un gran aporte no solo a la teoría jurídica latinoamericana, sino que es en cada declaratoria, la mejor vía para reintegrar a los seres humanos el principio básico y fundante del estado social de derecho, nos referimos a la dignidad humana, pues con este mecanismo se pretende mejorar la situación de la población más vulnerable del país.

Por tanto, sostenemos que la aplicación de la teoría expuesta dentro del presente artículo sirve de modelo y guía para los tribunales latinoamericanos, en especial para el Supremo Tribunal Federal a partir de la ADPF 347, pues además de representar un movimiento que permite hacer efectivas las garantías secundarias para hacer valer los derechos fundamentales, también permite optimizar el sistema jurídico del país, haciéndolo más coherente e integrado con los fines del Estado.

\section{REFERENCIAS}

ALVARADO, P. A. Diálogo judicial y constitucionalismo multinivel, el caso interamericano. Bogotá: Universidad del Externado de Colombia, 2015.

AMERICANOS, O. d. Convención Americana de Derechos Humanos. San José, Costa Rica : OEA, 1969.

BRASIL. Partido Socialismo y Liberdad. Petição inicial da Ação de Descumprimento de Preceito Fundamental 347. Disponible en: <http://jota.info/wp-content/uploads/2015/05/ ADPF-347.pdf>. Acceso en: 18 de junho de 2017.

Supremo Tribunal Federal. Acórdão no Recurso Extraordinário 580.252/MS. Relatoría: Teori Zavascki. Disponible en: <http://www.stf.jus.br/arquivo/cms/noticiaNoticiaStf/anexo/RE580252.pdf>. Acceso en: 18 de junho de 2017.

Supremo Tribunal Federal. Acórdão no Recurso Extraordinário 641.320/MS. Relatoría: Gilmar Mendes. Disponible en: < http://redir.stf.jus.br/paginadorpub/paginador. jsp?docTP=TP\&docID=11436372>. Acceso em: 18 de junho de 2017.

Supremo Tribunal Federal. Acórdão no Recurso Extraordinário 592.581/MS. Relatoría: Ricardo Lewandowski. Disponible en: <http://www.stf.jus.br/arquivo/cms/noticiaNoticiaStf/anexo/592581.pdf>. Acceso en: 18 de junho de 2017.

CAMPOS, C. A. Estado de Coisas Inconstitucional. 1ª edición. Salvador: Editora Juspodivm, 2016.

CEPEDA E. M. Grandes decisiones de la Corte Constitucional. Bogotá: Legis Editores S.A. 2001.

COLOMBIA. CONSTITUYENTE, A. N. Constitución política de Colombia, Bogotà, Colombia: Senado de la República, 20 de julio de 1991.

. Corte Constitucional de Colombia. Estado de cosas inconstitucional de la población desplazada, Sentencia T-025/04, Bogotá, Colombia, 22 de enero de 2004.

. Corte Constitucional de Colombia. Estado de cosas inconstitucional del sistema carcelario, Sentencia T-388/13, Bogotá, Colombia, 28 de junio de 2013.

. Corte Constitucional de Colombia. Establecimiento carcelario, condiciones de hacinamiento, Sentencia T-153/98, Bogotá, Colombia, 28 de abril de 1998. 
. Corte Constitucional de Colombia. Derecho a la seguridad social de persona de la tercera edad, Sentencia SU1023-01, Bogotá, Colombia, 26 de septiembre de 2001.

. Corte Constitucional de Colombia. Vulneración de los derechos fundamentales de las personas privadas de la libertad, Sentencia T-762/15, Bogotá, Colombia, 16 de diciembre de 2015.

. Informe del Gobierno Nacional a la Corte Constitucional sobre la superación del Estado de Cosas Inconstitucional declarado mediante sentencia T-025 de 2004. Sistema Nacional de Atención Integral a la Población Desplazada, SNAIPD. Bogotá D.C.: SNAIPD. 2010.

FERRER MG.P.E. Impacto de las sentencias de la Corte Interamericana de Derechos humanos y las víctimas de violación de derechos humanos. México, IIJ UNAM, 19 de febrero de 2013.

JARAMILLO, L. G. Constitucionalismo deliberativo. Estudio sobre el ideal deliberativo de la democracia y la dogmática constitucional del procedimiento parlamentario. México, D.F.: IIJ-UNAM, 2015.

KELSEN. H. La garantía jurisdiccional de la constitución. México, D.F. IIJ-UNAM, 2001.

MARTÍNEZ-CARANDE, E. G. La constitución como norma y tribunal constitucional. Madrid: Civitas, 2006.

MONTESQUIEU.C. B. Del espíritu de las leyes. México, D.F.: Porrúa, 2015.

NÚÑEZ, C. B. México-Colombia: dos décadas de distancia del nuevo constitucionalismo latinoamericano. Bogotá, Revista Derecho y Sociedad, 6, 2013.

OFICINA EN MÉXICO DEL ALTO COMISIONADO DE NACIONES UNIDAS. "El estado de cosas inconstitucional" en Un diálogo entre jueces, En G. M. Martelo, Trabajos de la Cumbre de Presidentes de Cortes Supremas, Constitucionales y Regionales. México, D.F. SCJN, 2014.

QUINTANA, O. M. Dos décadas de la constitución del 91: cronología de una constitución sitiada. En Memorias del XI Congreso Nacional de Filosofía del Derecho y Filosofía Social. Bogotá: Universidad Libre, 2012.

QUINTERO, L. J. La figura del estado de cosas inconstitucionales como mecanismo de protección de los derechos fundamentales de la población vulnerable en Colombia, Cartagena, Revista juriìdica Mario Alario D’Filippo, 72, 2011.

RAMÍREZ, M. Q. Derecho constitucional colombiano. De la carta de 1991 y sus reformas (5ta ed.). Bogotá: Temis, 2012.

SARLET, Ingo Wolfgang et al. Curso de direito constitucional. São Paulo: Saraiva, 2015. 